\title{
Peluang dan Tantangan Promosi Kesehatan Kader Kesehatan Remaja Kota Bogor
}

\author{
Siti Khodijah Parinduri ${ }^{1}$, Andi Asnifatima ${ }^{2}$, Muhammad Amin Arigo Saci ${ }^{3}$, \\ Andreanda Nasution ${ }^{4}$ \\ 1,2,4Program Studi Kesehatan Masyarakat,Fakultas IImu Kesehatan, Universitas Ibn Khaldun Bogor \\ Jln. Sholeh Iskandar KM 2 Bogor \\ ${ }^{3}$ Fakultas Kesehatan Masyarakat, Universitas Sriwijaya \\ Email: siti.parinduri@uika-bogor.ac.id', asni@uika-bogor.ac.id², \\ muhammadaminarigosaci@fkm.unsri.ac.id³ , andreanda@uika-bogor.ac.id ${ }^{4}$
}

\begin{abstract}
Abstrak
Masalah kesehatan terus berkembang diantaranya ialah masalah kesehatan yang dapat dicegah melalui perubahan gaya hidup yaitu obesitas meningkat dari 14 , \% menjadi $21,8 \%$ dan hampir seluruh penyakit tidak menular yang terus meningkat. Partisipasi kader remaja dalam pelaksanaan upaya kesehatan bagi anak usia sekolah dan remaja bertujuan untuk memupuk kebiasaan hidup sehat. Penelitian bertujuan untuk menemukan peluang dan tantangan kader kesehatan remaja kota Bogor dalam promosi kesehatan tahun 2020. Metode kualitatif dengan desain studi kasus yang dilakukan pada bulan Mei-Agustus 2020. Pengumpulan data dilakukan melalui survey online, wawancara dan focus group discussion (FGD) kepada informan yang terdiri dari petugas puskesmas, pelatih PMR, anggota PMR, pembina Saka Bakti Husada, pembina komunittas kesehatan IMAGO, dan ketua KSR. Hasil penelitian menunjukkan bahwa peluang terdiri dari bentuk kegiatan beragam, dukungan pihak terkait, teknologi, kebijakan yang mendukung partisipasi remaja dan keterlibatan remaja. Tantangannya ialah, manajemen waktu, konsistensi pelaksanaan kegiatan, pendampingan yang berkelanjutan. Peluang dan tantangan tersebut perlu dioptimalkan serta dihadapi dengan baik untuk mengoptimalkan peran promosi kesehatan kader kesehatan remaja.
\end{abstract}

Kata Kunci: Kader, promosi kesehatan, remaja

\begin{abstract}
Health problems continue to grow, including health problems that can be prevented through lifestyle changes, namely obesity increased from $14 \%$ to $21.8 \%$ and almost all non-communicable diseases continue to increase. The participation of youth cadres in implementing health efforts for school age children and adolescents aims to cultivate healthy habits. The research aims to find opportunities and challenges for Bogor youth health cadres in health promotion in 2020. Qualitative method with a case study design conducted in May-August 2020. Data collection was carried out through online surveys, interviews and focus group discussions (FGD) with informants consisting of primary health care officers, PMR trainers, PMR members, supervisors of Saka Bakti Husada, IMAGO health community coaches, and the chairman of the KSR. The results show that opportunities consist of various forms of activities, support from related parties, technology, policies that support youth participation and youth involvement. The challenges are, time management, consistency in the implementation of activities, sustainable mentoring. These opportunities and challenges need to be optimized and handled properly to optimize the health promotion role of youth health cadres.
\end{abstract}

Keywords: Cadres, health promotion, adolescents 


\section{Pendahuluan}

Indonesia memiliki masalah
kesehatan yang terus berkembang diantaranya adalah gizi buruk dan penyakit tidak menular yang mengakibatkan beban kesehatan terus meningkat. Riset Kesehatan Dasar (Riskesdas) 2018, mencatat bahwa Kementerian Kesehatan hanya mampu mengurangi angka stunting dari $37,2 \%$ menjadi $30,8 \%$ selama lima tahun, sedangkan gizi buruk dari 19,6\% menjadi $17,6 \%$ yang menunjukkan penurunan yang masih belum signifikan. ${ }^{1}$ Berdasarkan Indeks Pembangunan Kesehatan Masyarakat sub indeks yang terrendah Provinsi Jawa Barat adalah penyakit tidak menular $(0,4302)$. Hampir semua sub indeks mengalami peningkatan, terjadi kondisi yang lebih memburuk pada capaian indikator penyusun sub indeks penyakit tidak menular. ${ }^{2}$

Ketidaktahuan mengenai informasi tentang gizi dapat menyebabkan kurangnya mutu atau kualitas gizi makanan keluarga. Salah satu penyebab gangguan gizi adalah kurangnya pengetahuan gizi dan kemampuan seseorang menerapkan informasi tentang gizi dalam kehidupan sehari-hari. Tingkat pengetahuan gizi ibu memengaruhi sikap dan perilaku dalam memilih bahan makanan, yang lebih lanjut akan memengaruhi keadaan gizi keluarganya. $^{3} \quad$ Faktor yang menjadi penyebab penyakit tidak menular diantaranya adalah gaya hidup, pola makan dan aktivitas fisik. ${ }^{4}$ Masalah ini merupakan masalah yang dapat dicegah melalui perubahan perilaku atau pola hidup sehat sehingga dapat menahan laju masalah kesehatan.

Permenkes Nomor 25 Tahun 2014 tentang Upaya Kesehatan Anak pasal 28 yang mengamanatkan pelayanan kesehatan anak usia sekolah dan remaja melibatkan kader kesehatan sekolah dan konselor sebaya serta pasal 30 yang mengamanatkan partisipasi remaja dalam melakukan pelayanan kesehatan peduli remaja. Salah satu bentuk partisipasi kader anak usia sekolah dan remaja dalam pelaksanaan upaya kesehatan bagi anak usia sekolah dan remaja bertujuan untuk memupuk kebiasaan hidup sehat agar memiliki pengetahuan, sikap dan keterampilan untuk melaksanakan prinsip hidup sehat aktif berpartisipasi dalam program peningkatan kesehatan, baik di sekolah, di rumah maupun dalam lingkungan masyarakat. ${ }^{5}$

Kader Kesehatan Remaja adalah remaja yang dipilih atau secara sukarela mengajukan diri untuk ikut melaksanakan upaya pelayanan kesehatan terhadap diri sendiri, teman, keluarga, serta masyarakat. Kader Kesehatan Remaja (KKR) terdiri dari Konselor sebaya, Dokter Kecil, Pendidik Sebaya (Peer Educator), Anggota Saka Bhakti Husada, Anggota PMR, Anggota Karang Taruna, Kader Posyandu Remaja, Remaja Mesjid, Pemuda Gereja, dan Kader Jumantik Cilik. ${ }^{6}$

Prevalensi penyakit tidak menular berdasarkan hasil Riskesdas 2018 Kota Bogor memiliki prevalensi penyakit tidak menular yang lebih tinggi dari prevalensi provinsi Jawa Barat, seperti prevalensi diabetes melitus, hipertensi, dan asma. Berdasarkan data Riskesdas tahun 2018, prevalensi Diabetes Melitus Kota Bogor berdasarkan diagnosis dokter pada penduduk semua umur menurut Kabupaten/Kota ialah 1,54 dan prevalensi Jawa Barat ialah 1,28. ${ }^{7}$ Data Indeks Pembangunan Kesehatan Masyarakat menunjukkan bahwa sub indeks yang terendah adalah penyakit tidak menular $(0,4302)$, sub indeks penyakit tidak menular terjadi penurunan nilai yang cukup banyak. Artinya, terjadi kondisi yang lebih memburuk pada capaian indikator penyusun sub indeks penyakit tidak menular. $^{2}$

Penelitian sebelumnya diantaranya ialah Sarweni meneliti terkait demand dan supply program kesehatan remaja di Puskesmas Tanah Kalikedinding Surabaya dengan metode kualitatif menghasilkan kesimpulan bahwa remaja membutuhkan kegiatan yang tidak hanya bersifat kuratif. ${ }^{8}$ Pelayanan yang efektif menurut remaja dapat dilakukan dengan pemanfaatan 
informasi teknologi (IT) melalui penggunaan media sosial berupa facebook, twitter atau menggunakan pesan singkat melalui BBM, sms agar petugas kesehatan maupun remaja tidak terhalang oleh waktu yang terbatas. ${ }^{9}$ Penelitian ini bertujuan untuk menemukan peluang dan tantangan kader kesehatan remaja kota Bogor dalam promosi kesehatan tahun 2020.

\section{Metode}

Metode penelitian yang digunakan adalah kualitatif dengan desain studi kasus. ${ }^{10}$ Teknik pengumpulan data primer yang digunakan: desk study, survey online, wawancara dan FGD. Teknik analisis data yang digunakan adalah Content Analysis. Desk study dilakukan untuk memperoleh gambaran dan input mengenai kegiatan promosi kesehatan yang telah dilakukan kader kesehatan remaja yang diperoleh dari literatur review, survey online dilakukan untuk mengumpulkan karakteristik remaja, ketertarikan, dan bentuk kegiatan promosi kesehatan remaja yang ada dan diminati oleh remaja, wawancara mendalam dilakukan untuk memperoleh informasi mendalam mengenai kegiatan kader kesehatan remaja, peluang dan tantangannya, dan FGD digunakan untuk mengumpulkan informasi mendalam dari anggota PMR mengenai pelaksanaan kegiatan kader kesehatan remaja. FGD dilakukan secara online dengan menggunakan aplikasi meeting online pada kelompok pengurus PMR di Kota Bogor pada bulan Agustus tahun 2020.

Informan pada penelitian ini adalah petugas puskesmas, pelatih PMR, anggota PMR, pembina Saka Bakti Husada, pembina komunittas kesehatan IMAGO, dan ketua KSR. Kemudian hasil analisis konten tersebut dilanjutkan dengan menganalisis peluang dan tantangan. Triangulasi dilakukan ialah triangulasi metode dan sumber. Triangulasi metode dilakukan dengan menggunakan metode survey online, wawancara dan focus group discussion dan triangulasi sumber dilakukan dengan melakukan wawancara kepada pelatih PMR, Ketua KSR dan pembina SBH.

Tahapan yang dilakukan oleh peneliti ialah melakukan desk study, survey online, kemudian melakukan wawancara mendalam dan FGD. Hasil pengumpulan data tersebut kemudian dianalisis oleh peneliti dan tim pakar yaitu seorang psikolog untuk mengetahui peluang dan tantangan promosi kesehatan bagi remaja dari sudut pandang psikologi sehingga dapat memperkuat rekomendasi untuk remaja dan stakeholder selain berdasarkan hasil analisis penulis dari perspektif kesehatan masyarakat.

\section{Hasil dan Pembahasan}

Hasil studi literatur menunjukkan bahwa di berbagai kota memiliki kegiatan pemberdayaan remaja beraneka ragam, terdapat pula berbagai wadah untuk remaja berkontribusi dalam meningkatkan perannya untuk kesehatan masyarakat melalui kegiatan-kegiatan yang dekat dengan remaja, seperti melalui pendekatan sekolah dalam kegiatan ekstrakulikuler bidang kesehatan. Pengumpulan data dilakukan melalui online kepada remaja di Kota Bogor melalui survey cepat untuk memberikan gambaran kader kesehatan remaja di kota Bogor. Pada survey tersebut diklasifikasikan remaja berdasarkan BKKBN yaitu 10-24 tahun dengan memberikan beberapa pertanyaan terkait kegiatan kader kesehatan remaja. Hasil survey online tersebut diisi oleh 112 responden remaja.

Hasil survey online menunjukkan bahwa remaja yang berusia 10-24 tahun berdasarkan Pendidikan yang sedang ditempuh terdiri dari siswa/mahasiswa SD (21\%), SMP (13\%) SMA (46\%) dan perguruan tinggi $(21 \%)$. Responden yang mengaku ikut serta dalam komunitas kesehatan sebanyak $53(47 \%)$ responden. Responden terbanyak yang mengisi adalah anggota PMR (45\%) dan yang paling sedikit adalah kategori karang taruna, dan kader Posyandu remaja. Minat kader kesehatan remaja dalam mengikuti kegiatan kader kesehatan remaja sangat 
Tabel 1. Gambaran Karakteristik Kader Kesehatan Remaja Kota Bogor

\begin{tabular}{|c|c|c|c|}
\hline Variabel & Kategori & $\mathbf{n}$ & $\%$ \\
\hline \multirow[t]{4}{*}{ Pendidikan } & SD & 23 & 21 \\
\hline & SMP & 15 & 13 \\
\hline & SMA & 51 & 46 \\
\hline & Perguruan Tinggi & 23 & 21 \\
\hline \multirow{2}{*}{$\begin{array}{l}\text { Keikutsertaan Remaja dalam } \\
\text { Komunitas Kesehatan }\end{array}$} & $\mathrm{Ya}$ & 53 & 47 \\
\hline & Tidak & 59 & 53 \\
\hline \multirow[t]{13}{*}{ Kategori KKR } & Palang Merah Remaja & 36 & 45 \\
\hline & Dokcil & 5 & 6 \\
\hline & Saka Bakti Husada & 2 & 3 \\
\hline & Remaja Masjid & 8 & 10 \\
\hline & Komunitas Kesehatan Kota & & \\
\hline & Bogor & 1 & 1 \\
\hline & Konselor Sebaya & 15 & 19 \\
\hline & Anggota Karang Taruna & 3 & 4 \\
\hline & Duta Muda Sehat & 2 & 3 \\
\hline & Kader Posyandu Remaja & 1 & 1 \\
\hline & Pendidik Sebaya (Peer & & \\
\hline & Educator) & 5 & 6 \\
\hline & Anggota UKS & 2 & 3 \\
\hline \multirow[t]{3}{*}{ Dukungan Pihak lain } & $\mathrm{Ya}$ & 38 & 72 \\
\hline & Tidak & 0 & 0 \\
\hline & Mungkin & 15 & 28 \\
\hline \multirow[t]{2}{*}{ Pelibatan KKR dalam Komunitas } & Ya & 43 & 81 \\
\hline & Tidak & 10 & 19 \\
\hline
\end{tabular}

beragam ada yang menyatakan sangat menyukai sebanyak 25 (47\%) responden. Dukungan pihak lain terhadap kegiatan kader kesehatan remaja $72 \%$ menyatakan bahwa mendapat dukungan. Mayoritas responden $(81 \%)$ juga menyatakan bahwa merasa dilibatkan dalam kegiatan-kegiatan kader kesehatan remaja.

Hasil wawancara mendalam yang dilakukan kepada pembina SBH, pelatih PMR, ketua KSR, petugas puskesmas, anggota PMR, pembina komunitas kesehatan IMAGO kota Bogor dan FGD yang dilakukan pada pengurus PMR SMP dan SMA menyatakan bahwa peran remaja sebagai kader kesehatan remaja memiliki beragam jawaban peran dalam wadahwadah organisasi maupun komunitas sekolah diantaranya ialah menjadi contoh di lingkungan sekolah dan masyarakat dalam menerapkan hidup sehat.

Peran kader kesehatan remaja lainnya diantaranya adalah turun ke masyarakat, menghimbau dan mendorong hidup sehat dan bersih. Bagi duta kesehatan sendiri adanya duta muda sehat menjadi salah satu upaya untuk membantu peran promkes di masyarakat dan menemukan masalah-masalah kesehatan yang ada di masyarakat untuk selanjutnya dapat ditindaklanjuti dinas kesehatan.

\section{"Kalo PMR sendiri kita punya program- program kesehatan dan program sekolah, itu yang paling penting adalah menghimbau. Selain menghimbau juga memastikan orang- orang di sekolah bener-bener mentaati peraturan di sekolah dan tidak melanggarnya gitu, kayak missalnya setiap sabtu ngadain program buat bersih-bersih atau ga seperti kita bikin program mading himbauan menjaga kesehatan buat ngasih tau pentingnya menjaga kesehatan." (Pengurus PMR 1)}

Hasil wawancara duta kesehatan Kota Bogor menjelaskan bahwa dalam menjalankan perannya sebagai kader kesehatan remaja, menunjukkan kepada remaja mengenai masalah-masalah yang 
ditemukan di masyarakat terkait kesehatan masyarakat, sebagaimana dalam kutipan hasil wawancara berikut ini:

"Keluhan masyarakat misalkan di Bogor Selatan itu khususnya kertamaya masih ada kuratif persalinan non pelayanan kesehatan bukan di Puskesmas atau Rumah Sakit kaya gitu, kalau dari dinas data waktu itu $v$ pernah dapet terakhir bulan Desember terus aaa... ini sudah masuk mulai anu gitu maksudnya selangnya masih jauh yang data itu dan kita coba buat lebih berperan turun ke masyarakat, intinya sih lebih membantu untuk membantu dinas ketika personil dari anggota promkesnya itu kurang gitu, karena $v$ engga tau berapa banyak dari promkes karyawan disananya tapi bidang promkes itu menyelenggarakan duta muda sehat ini untuk membantu bidang promkes"(Duta Kesehatan Kota Bogor)

Peran kader kesehatan remaja bagi kader kesehatan remaja yang tergabung dalam KSR juga memperkuat pernyataan petugas PMR dan duta kesehatan Kota Bogor bahwa remaja memiliki peran sosial dalam mendorong pelayanan kesehatan khususnya dalam kegiatan donor darah dalam jaringan nasional.

"perannya KSR kan lebih ke masyarakat, tapi untuk programnya lebih ke bakti social terus kayak donor darah, lomba-lomba juga jadi kan menarik perhatiaan untuk adik-adik kita juga di PMR, terus ada juga dari KSR sini ke KSR jabodetabek bahkan ke Indonesia sendiri jadi lebih mencakup semuanya sih"(Ketua KSR)

Bagi pembina sendiri, SBH sebagai salah satu kader Kesehatan remaja anggota SBH memiliki peran penting dalam mengedukasi masyarakat khususnya melalui sekolah-sekolah agar para remaja memiliki pengetahuan yang diterapkan dan menjadi contoh di masyarakat.

"Perannya sendiri sekarang kalau dari dulu kader remaja mereka turun langsung ke masyarakat didampingi sama para praktisipraktisi kesehatan atau promkes-promkes di Puskesmas didampingi ke masyarakat dan diajak ikut dalam lokmin, dalam kelas ibu dan sebagainya gitu kan, itu mereka juga ikut membantu mensosialisasikan hidup sehat begitu. ......Jadi sebelum dia mengedukasi pun mereka harus jadi contoh yang baik di masyarakat baru mengedukasi." (Pembina SBH kota Bogor)

Kader Kesehatan Kota Bogor terdiri beberapa kategori diantaranya pengurus PMR, Saka Bakti Husada, KSR, Komunitas Kesehatan IMAGO. Bentuk kegiatan kader kesehatan remaja diantaranya dalam bentuk lomba, donor darah, pelatihan, dan forum diskusi antar remaja. Pernyataan ini sesuai dengan hasil wawancara dengan informan sebagai berikut:

\begin{abstract}
"Kayak lomba, donor darah, pelatihan nasional terus ada juga forum, forumnya itu buat forum-forum diskusi aja, pelatihan workshop materi pertolongan pertama, piket-piket di markas"(Ketua KSR)

"Kalau hari sabtu kita belajar tentang PP (Pertolongan Pertama) terus kayak belajar tentang pendidikan remaja sebaya, bagaimana cara orang kalo patah tulang tuh kayak gimana terus juga gimana caranya biar kita tetep kompak. Kalau untuk diluar sih biasanya kita ikut lomba, biasanya sih di SMKN 1 ada kegitan perlombaan contohnya tuh mawilaga asih muda"'(Pengurus PMR 2)
\end{abstract}

Metode yang digunakan bermacammacam diantara metode yang ada beberapa metode yang direkomendasikan oleh pelatih PMR, pengurus PMR, duta kesehatan kota Bogor maupun pembina SBH adalah metode ceramah dengan adanya stimulan penghargaan dan diskusi dengan pendekatan remaja, adanya pelibatan remaja dalam menganalisis kondisi lingkungan sekitar remaja, dan konsultasi remaja dengan meningkatkan peran guru BK. Pernyataan ini sesuai dengan hasil wawancara dengan informan sebagai berikut:

\footnotetext{
"Metodenya sih pengennya kita kayak ngumpulin anak-anak gitu, pengennya sih ngumpulin satu sekolah dilapangan. Nah nanti kita anak-anak PMRnya tuh memberi edukasi gitu kayak ngasih tau, pengennya sih gitu."(Pengurus PMR2)

"sebenernya remaja itu harus ada yang kita berikan stimulan-stimulannya itu adalah sebuah penghargaan” (Duta Kesehatan
} 


\begin{abstract}
Kota Bogor)
"Kalau misalnya bisa di gerakkan lebih dalam lagi atau lebih sering lagi, kader remaja ini lebih banyak aktifitas yang memang harus turun ke lapangan, lebih menganalisis bagaimana kebutuhannya masyarakat dan nanti mereka juga dilibatkan dalam membuat kebijakan atau membuat program untuk masyarakatnya sendiri." (Pembina SBH)

"Menurut saya kegiatan yang perlu dioptimalkan itu emm pertama di lomba, di lomba itu kita bener-bener harus optimalin biar nama ekskul kita itu dikenal sama banyak sekolah di luar sana selain itu kita juga harus lebih sering ngadain acaraacara kayak penggalangan dana karena kan basic nya kita adalah organisasi kemanusiaan atau organisasi di bawah PMR bawahnya PMIyang berkecimpung mau ga mau sama dunia kesehatan. (Pengurus PMR 1)"
\end{abstract}

Tantangan dalam pelaksanaan kegiatan bagi wadah kader kesehatan remaja diantaranya adalah manajemen waktu, komitmen dan konsistensi, remaja harus mampu menyesuaikan dengan jadwal sekolah, sehingga kegiatan kader kesehatan remaja dapat berjalan tanpa mengganggu jadwal pembelajaran sekolah. Adanya waktu yang beragam dari remaja mengakibatkan kegiatan kader kesehatan remaja dapat dilakukan pada hari libur sekolah seperti Sabtu dan Minggu. Pernyataan ini sesuai dengan hasil wawancara dengan informan sebagai berikut:

"Kalau menurut saya sih yang ngebuat kayak kendalanya itu harus ada izin orangtua, trus cocok atau enggaknya sama jadwal aktivitas yang lain, trus kita harus kasih tau orangtua pulangnya jam berapa, kegiatannya itu apa, dan itu pun harus kayak ditepatin gitu, ya harus konsisten sama tanggung jawab lah"(F5)

"Dari segi waktu sih, kadang kita ga bisa nyesuain waktu sama mereka" (Ketua KSR)

"Kalo waktu lebih banyak sih bermasalahnya, karna apa kalo disekolah mereka kan terbentur dengan kita" (Petugas Puskesmas Tanah Sareal)

"Tantangannya sih paling menjaga komitmen mereka ya karna kan ini enam bulan kita bikin programnya itu jadi agak sulit, kan tadinya dilaksanainnya weekend ya karna kalau weekday kan mereka sekolah" (Pembina Komunitas Kesehatan IMAGO Bogor)

Tantangan lainnya adalah selama masa pandemic Covid-19, kegiatan kader kesehatan remaja melalui online dimana remaja memiliki keterbatasan dalam memiliki akses jaringan yang stabil dan kuota yang memadai dalam mengikuti kegiatan secara online. Tantangan ini perlu dijawab bersama oleh stakeholder agar dapat meminimalisir keterbatasan yang ada.

"Kendalanya pasti sinyal, trus kedua juga kalo misalnya kita pertemuan online atau daring biasanya anak-anak kendala dari sinyal mereka atau kuota mereka yang abis, itu aja sih bu. "(Pelatih PMR)

Kader Kesehatan Remaja aktif yang diperoleh dari 23 artikel ialah KKR Sekolah (UKS) SMP, Pendidik Sebaya (Peer ducator), Anggota Karang Taruna, Remaja Masjid, Pemuda Gereja, Pendidik Sebaya (Peer Educator), Anggota Palang Merah Remaja, Kader Posyandu Remaja, Kader Jumantik Cilik, Konselor Sebaya, Dokter Kecil, Anggota Saka Bakti Husada. Kegiatan kader kesehatan remaja telah berjalan antara 2017-2018 menunjukkan bahwa kegiatan promosi kesehatan telah dilakukan terhadap remaja untuk mendekatkan informasi kesehatan melalui kegiatan orientasi kader kesehatan remaja, pelatihan, pendampingan, peningkatan pelayanan kesehatan berbasis keagamaan (masjid dan gereja). Kegiatan kader kesehatan remaja juga melakukan inovasi dan pengembangan di beberapa wilayah, optimalisasi peran kader kesehatan remaja selain dilakukan dengan peningkatan pengetahuan dan keterampilan remaja dilakukan pula upaya menciptakan lingkungan yang mendukung seperti pengadaan sarana Upaya Kesehatan Sekolah dengan swadaya. Pihak yang terlibat dalam kegiatan-kegiatan kader kesehatan remaja menjadi salah satu faktor yang turut berperan, pihak tersebut diantaranya Guru, dinas kesehatan, klinik 
swasta, Puskesmas, Tim Pengabdian Masyarakat Universitas, Pemerintah Daerah, Dewan Masjid Indonesia, Badan Penyelenggara Jaminan Sosial Kesehatan, Gereja, Yayasan, Petugas Promkes , Kemendikbud, Dancow Fortigro, Orangtua, dan Praktik Dokter Swasta. Hasil analisis kegiatan kader kesehatan remaja Kota Bogor menunjukkan bahwa remaja sebagai kader kesehatan remaja memiliki berbagai macam wadah yang terdiri dari berbagai bentuk kegiatan dan pendekatan yang berbeda-beda. Wadah yang ada seperti PMR, SBH, duta muda kesehatan, komunitas kesehatan IMAGO dan SBH menjadi peluang dalam mengembangkan metode-metode kegiatan yang lebih kreatif dalam meningkatkan partisipasi remaja terhadap peningkatan derajat kesehatan masyarakat melalui peran aktif remaja. Wadah tersebut memiliki kekhasan masing-masing, seperti memperoleh edukasi yang intensif mengenai pertolongan pertama, kesehatan reproduksi ataupun promosi kesehatan di masyarakat. Bentuk kegiatan remaja setelah adanya pandemi pun mengalami perubahan sehingga seluruh kegiatan dilakukan secara online juga menjadi tantangan baru agar terus berjalan meskipun melalui media online. Pada penelitian lainnya pelatihan kader kesehatan remaja (KKR) menjadi hal yang penting dalam kegiatan Usaha Kesehatan Sekolah (UKS) karena terbukti dapat meningkatkan capaian indikator kesehatan sekolah. $^{11}$

Peluang terdiri dari bentuk kegiatan yang beragam, dukungan pihak terkait, teknologi, kebijakan yang mendukung partisipasi remaja, stimulan maupun apresiasi dan keterlibatan remaja. Bentuk kegiatan kader kesehatan remaja PMR terdiri dari kerja bakti untuk kampanye lingkungan bersih, mading yang berisi himbauan dan pesan kesehatan, belajar mengenai pertolongan pertama (simulasi), pendidikan remaja sebaya, team building dan perlombaan yang mendorong semangat remaja. Kegiatan tersebut mendukung adanya promosi kesehatan dari, oleh dan untuk remaja dengan menggunakan berbagai metode dan pendekatan dilakukan melalui sekolah dan komunitas. Pada kegiatan ini selain mendukung adanya peningkatan pengetahuan, remaja juga didorong untuk mewujudkannya dalam bentuk tindakan dan menjadi contoh untuk remaja lain dan masyarkat pada umumnya. Keterlibatan remaja yang lebih besar mendorong identifikasi masalah kesehatan dan pengembangan solusi yang tepat, mereka juga akan lebih terlihat oleh komunitas, pemangku kepentingan, dan pengambil keputusan. $^{12,13}$ Hal ini menunjukkan adanya konsistensi dari penelitian sebelumnya yang menunjukkan bahwa keterlibatan remaja memberikan dampak positif terhadap upaya kesehatan masyarakat.

Salah satu wadah lainnya adalah duta muda kesehatan kota Bogor sebagai salah satu kader kesehatan remaja yang berperan langsung menjadi agen promosi kesehatan di masyarakat dengan menggunakan metode simulasi dapat menyebabkan kader kesehatan remaja belajar memahami kegiatan dan memberi kesempatan berlatih mengambil keputusan. ${ }^{14}$ Duta muda kesehatan berada langsung dibawah promosi kesehatan Dinas Kesehatan Kota Bogor. Duta muda kesehatan terdapat di setiap kecamatan yang kemudian saling berkoordinasi sebagai duta muda kesehatan kota Bogor. Kegiatan yang dilakukan ialah promosi kesehatan kepada masyarakat dan melakukan analisis situasi kesehatan di masing-masing wilayah. Komunitas Kesehatan IMAGO juga menjadi salah satu komunitas remaja yang mengumpulkan siswa dari berbagai sekolah yang memperoleh pelatihan secara intensif dan menjadi agen bagi sekolahnya. Hal ini sejalan dengan penelitian yang menyatakan bahwa melalui komunitas remaja menunjukkan bahwa remaja memperoleh keterampilan baru dalam kerja tim dan komunikasi. ${ }^{15}$ Wadah bagi kader kesehatan remaja sangat beragam baik dari 
pemerintah maupun swadaya masyarakat. Intervensi kesehatan masyarakat dapat memperoleh manfaat dari peluang pemberdayaan yang terpusat bagi kaum muda. $^{16}$

Tantangan kader kesehatan remaja diantaranya adalah manajemen waktu, konsistensi pelaksanaan kegiatan, pendampingan yang berkelanjutan. Remaja dengan kegiatan utama sekolah memiliki tantangan dalam mengelola antara waktu sekolah dan kegiatan kader kesehatan remaja. Apabila sekolah tidak memberikan dukungan dalam memberikan alokasi waktu remaja untuk melakukan kegiatan kader kesehatan remaja maka akan sulit untuk membangun komitmen dari remaja itu sendiri. Dukungan pihak lainnya menjadi salah satu solusi dalam menjawab tantangan kader kesehatan remaja agar dapat terus optimal dalam menjalankan peran sebagai kader kesehatan remaja.

\section{Kesimpulan}

Kader kesehatan remaja kota Bogor tahun 2020 dan pada masa pandemi memiliki peluang untuk terus berkembang dan mengoptimalkan peran melalui berbagai wadah kegiatan remaja, pendekatan remaja, dukungan berbagai stakeholder, dan kegiatan remaja yang terus berkembang. Tantangan yang dihadapi ialah manajemen waktu, konsistensi pelaksanaan kegiatan, pendampingan yang berkelanjutan dan jaringan komunikasi online. Peluang dan tantangan tersebut perlu dioptimalkan serta dihadapi dengan baik untuk mengoptimalkan peran promosi kesehatan kader kesehatan remaja. Peran remaja tersebut perlu dikaji kembali untuk mengoptimalkan integrasi antara wadahwadah kader kesehatan remaja yang sudah ada. Penelitian selanjutnya dapat mengembangkan analisis stakeholder dan keberlanjutan dengan sasaran kelompok remaja yang lebih spesifik untuk menghasilkan gambaran yang lebih mendalam.

\section{Daftar Pustaka}

1. Balitbang Kemenkes. Riset Kesehatan Dasar 2018. Jakarta; 2018.

2. Kementerian Kesehatan RI. Indeks Pembangunan Kesehatan Masyarakat 2018. Lembaga Penerbit Badan Penelitian dan Pengembangan Kesehatan. 2019.

3. Suhardjo. Berbagai cara pendidikan gizi. Jakarta: Bumi Aksara; 2003.

4. Wiwin Efrizal. Berdampakkah pandemi covid19 terhadap stunting di bangka belitung? 2020;09(03):154-7.

5. Kesehatan M. Permenkes no 25 tahun 2014 Upaya Kesehatan Anak. 2014; Available from: https://repositories.lib.utexas.edu/handle/2152/ 39127\%0Ahttps://cris.brighton.ac.uk/ws/porta lfiles/portal/4755978/Julius+Ojebode $\% 27 \mathrm{~s}+\mathrm{T}$ hesis.pdf\%0Ausir.salford.ac.uk/29369/1/Angel a_Darvill_thesis_esubmission.pdf $\% 0$ Ahttps:// dspace.lboro.ac.uk/dspace-jspui/ha

6. Kesehatan K. Buku KIE Kader Kesehatan Remaja. Shafiyyah LSRSC, editor. Jakarta: Kementerian Kesehatan RI; 2018.

7. Kementerian Kesehatan RI. Laporan Provinsi Jawa Barat, Riskesdas 2018. Lembaga Penerbit Badan Penelitian dan Pengembangan Kesehatan. 2019. 140-151 p.

8. Sarweni KP, Hargono R, Masyarakat FK, Airlangga U. Demand Vs Supply Program Kesehatan Remaja Di Puskesmas Tanah Kalikedinding Surabaya Demand Vs Supply Adolescent Health Program In Puskesmas. 2010;71-81.

9. Rohmayanti. Pelayanan Kesehatan Peduli Remaja Menurut Perspektif Remaja di Kota Magelang. J Kesehat Reproduksi. 2014;

10. Creswell JW. Penelitian Kualitatif \&Desain Riset. Yogyakarta: Pustaka Pelajar.; 2014.

11. Dewi IP, Sanusi S, Maryati I. Pelatihan Kader Kesehatan Remaja untuk Meningkatkan Capaian Indikator Sehat Siswa/I di Pondok Pesantren. ABDIMAS J Pengabdi Masy. 2019;2(1):86-90.

12. Sawyer SM, Afifi RA, Bearinger LH, Blakemore SJ, Dick B, Ezeh AC, et al. Adolescence: A foundation for future health. Lancet. 2012;379(9826):1630-40.

13. Lowndes V, Pratchett L. CLEAR: Understanding Citizen Participation in Local Government - and How to Make it Work Better Vivien Lowndes and Lawrence Pratchett The CLEAR model. 2014;(May).

14. Ristanto R. Pengaruh Pendidikan Kesehatan Dengan Metode Simulasi Terhadap Pengetahuan Dan Ketrampilan Dokter Kecil Pada Penanganan Luka Terbuka. J Kesehat Mesencephalon. 2019;5(2).

15. Sales JM, Tamler I, Powell L, Tschokert M. Community-Based Participatory Research As Positive Youth Development For Adolescents: 
Findings From The Atlanta Youth Research Coalition Project. J Adolesc Heal [Internet]. 2019;64(2):S25. Available from: https://doi.org/10.1016/j.jadohealth.2018.10.0 60

16. Ballard PJ, Cohen AK, Duarte C d. P. Can a school-based civic empowerment intervention support adolescent health? Prev Med Reports [Internet]. 2019;16(December 2018):100968. Available from: https://doi.org/10.1016/j.pmedr.2019.100968 